\title{
High-Impact Extratropical Cyclones along the Northeast Coast of the United States in a Long Coupled Climate Model Simulation
}

\author{
ARIELle J. CATALANO ${ }^{a}$ \\ Department of Environmental Sciences, Rutgers, The State University of New Jersey, New Brunswick, New Jersey
}

ANTHONY J. BROCCOLI

Department of Environmental Sciences, and Institute for Earth, Ocean, and Atmospheric Sciences, Rutgers, The State University of New Jersey, New Brunswick, New Jersey

SARAH B. KAPNICK

Geophysical Fluid Dynamics Laboratory, Princeton, New Jersey

TYLER P. JANOSKI

Department of Earth and Environmental Sciences, Columbia University, New York, New York

(Manuscript received 12 June 2018, in final form 28 January 2019)

\begin{abstract}
High-impact extratropical cyclones (ETCs) cause considerable damage along the northeast coast of the United States through strong winds and inundation, but these relatively rare events are difficult to analyze owing to limited historical records. Using a 1505-yr simulation from the GFDL FLOR coupled model, statistical analyses of extreme events are performed including exceedance probability computations to compare estimates from shorter segments to estimates that could be obtained from a record of considerable length. The most extreme events possess characteristics including exceptionally low central pressure, hurricane-force winds, and a large surge potential, which would greatly impact nearby regions. Return level estimates of metrics of ETC intensity using shorter, historical-length segments of the FLOR simulation are underestimated compared to levels determined using the full simulation. This indicates that if the underlying distributions of observed ETC metrics are similar to those of the 1505-yr FLOR distributions, the actual frequency of extreme ETC events could also be underestimated. Comparisons between FLOR and reanalysis products suggest that not all features of simulated high-impact ETCs are representative of observations. Spatial track densities are similar, but FLOR exhibits a negative bias in central pressure and a positive bias in wind speed, particularly for more intense events. Although the existence of these model biases precludes the quantitative use of model-derived return statistics as a substitute for those derived from shorter observational records, this work suggests that statistics from future models of higher fidelity could be used to better constrain the probability of extreme ETC events and their impacts.
\end{abstract}

\section{Introduction}

In the northeastern United States, extratropical cyclones (ETCs) are responsible for substantial devastation including many of the largest storm surge levels in recorded history (Catalano and Broccoli 2018,

\footnotetext{
${ }^{\text {a }}$ Current affiliation: Department of Geography, Portland State University, Portland, Oregon.
}

Corresponding author: Arielle J. Catalano, a.j.catalano@pdx.edu hereinafter CB18). Some of the most damaging ETCs exhibit exceptionally strong low-level winds or low central pressures. For example, the Storm of the Century in March 1993 experienced explosive cyclogenesis and deepened rapidly at a rate of over $1 \mathrm{hPah}^{-1}$ at an unusually low latitude (Kocin et al. 1995). This storm was associated with the sixth largest ETC-driven storm surge recorded at The Battery, New York (1920-2010), and the eleventh largest at Boston, Massachusetts (1921-2010), with wind gusts exceeding hurricane force at Boston and Fire Island, New York. Another 
high-impact ETC was the Great Appalachian Storm of November 1950 (Smith 1950), which produced powerful wind gusts over $60 \mathrm{~m} \mathrm{~s}^{-1}$ and generated the secondhighest storm surge at The Battery, exceeded only by Hurricane Sandy. By definition, examples of such storms are rare in the observational record. High-quality observations for synoptic-scale events are available extending back to the onset of the modern reanalysis era (1979), and the longest tide gauge records span approximately 100 years. Therefore, quantifying the risks of high-impact ETCs remains difficult, as it is highly unlikely that the most extreme ETC-driven storm surge events that are physically possible are captured in either of these records.

One approach to address the limitations of observational data is to develop a larger sample of ETCs through statistical modeling. Numerous models have been developed for tropical cyclone hazard assessments (Emanuel et al. 2006; Hall and Yonekura 2013). Lin et al. (2012) analyzed storm surge risk in New York City using a statistical-deterministic model to generate a large sample of tropical cyclones. The larger population of cyclones included surge-producing storms that do not appear in observations but may be possible, dubbed "grey swans" (Lin and Emanuel 2016). To examine the risks posed by ETCs, Hall and Booth (2017) developed a statistical-stochastic model trained on historical ETC tracks (1979-2015) to estimate rates of severe ETCs in North America, which included gray-swan-type events. However, the model does not simulate wind fields, so impacts associated with severe winds such as storm surge cannot be considered.

Large samples of ETCs that also include meteorological information for hazard assessment can be obtained from three-dimensional models of the atmospheric general circulation. We utilize this approach with a long (i.e., multicentury) simulation of current climate conditions from a coupled atmosphere-ocean general circulation model to identify unusual, highimpact ETCs. The larger number of realizations should provide a better opportunity to sample the tail of the distribution of high-impact ETC characteristics including severe winds and low central pressures. This work is presented as a demonstration of the potential value of a physically based sample of ETCs that is much larger than can be obtained from the observed record.

After a brief description of the model and methodology, results are divided into three sections. First, we establish the value of using a long integration to analyze the most extreme impacts associated with ETCs. Then, the circulation and propagation of notable high-impact ETCs are examined. Finally, the realism of simulated ETCs is evaluated through comparisons with a reanalysis product, and the implications of this research are discussed.

\section{Data and methodology}

The long simulation utilized in this work is from the Forecast-Oriented Low Ocean Resolution (FLOR) version of the Geophysical Fluid Dynamics Laboratory (GFDL) CM2.5 model (Vecchi et al. 2014). The simulation is 1505 years in length and incorporates radiative forcing and land-use conditions at 1990 levels to represent recent conditions. FLOR is a fully coupled global model that differs from the original CM2.5 model (Delworth et al. 2012) by virtue of its lower ocean resolution, which reduces computational expense so that long simulations (i.e., from centuries to millennia) can be run. The atmospheric component of FLOR has a horizontal resolution of $50 \mathrm{~km}$ with 32 vertical levels, whereas the ocean component has a nominal $1^{\circ}$ horizontal resolution, as in the earlier CM2.1 model (Delworth et al. 2006). Since we are most concerned with atmospheric characteristics of ETCs such as circulation patterns, the difference in ocean resolution should not substantially affect our results. Seasonal hindcasts using FLOR indicate that the model is capable of reproducing geographic features important to ETC development such as large-scale mean flow as well as storm track variability (Yang et al. 2015).

To detect and track high-impact ETCs, we use an algorithm developed at GFDL for tropical cyclones (Murakami et al. 2015; Harris et al. 2016) and modified to include ETCs. Criteria are outlined below:

- Using 6-hourly, instantaneous gridded data, potential storm centers are identified from the local minimum SLP, which has been shown to produce similar results in the western Atlantic Ocean compared to trackers using vorticity (Colle et al. 2013).

- To qualify as a cyclone, the area of low SLP must possess at least one closed contour (based on a contour interval of $4 \mathrm{hPa}$ ) and a central pressure no higher than $1021 \mathrm{hPa}$, which closely corresponds to the maximum of the distribution of central pressures of Northern Hemisphere ETCs (Hodges et al. 2011).

- The system must propagate at least $500 \mathrm{~km}$ and have a minimum lifetime of $24 \mathrm{~h}$.

Although other ETC trackers generally apply a minimum distance threshold of $1000 \mathrm{~km}$, we set a $500-\mathrm{km}$ limit. The slowest average propagation speed for clustered ETC-driven surge events in the northeastern United States is $6.6 \mathrm{~m} \mathrm{~s}^{-1}$ (see Table 3 in CB18). For 6-hourly data and a 24-h minimum lifetime requirement, an ETC propagating at $6.6 \mathrm{~m} \mathrm{~s}^{-1}$ travels a distance of approximately $570 \mathrm{~km}$. Since this is an average speed, 
the minimum distance is lowered to $500 \mathrm{~km}$ to include all potential high-impact cyclones. In addition, previous studies have applied lifetime thresholds ranging from 12 to $72 \mathrm{~h}$ (e.g., Gulev et al. 2001; Raible et al. 2008; Hoskins and Hodges 2002), but Colle et al. (2013) found $24 \mathrm{~h}$ to be optimal in the western North Atlantic. We are most concerned with capturing all high-impact ETCs, some of which have a short duration, so including brief or weak storms will not affect our analysis.

\section{Utility of a long integration for estimating probabilities of extreme events}

In this section, the utility of the larger record of highimpact events in the FLOR simulation for estimating probabilities of extreme events is explored. To estimate the return periods of the strongest events in the record, we employ the block maxima approach of the generalized extreme value (GEV) theorem (Coles 2001). The block maxima approach involves partitioning an observation period into equivalent segments over which the maximum value is computed. Then a GEV distribution is fit to these maximum values using maximum likelihood estimates of parameters (Prescott and Walden 1980). For our purposes, the most extreme value of the variable in question for each year of the simulation is selected, and a three-parameter GEV distribution is fitted to all 1505 values using maximum likelihood estimation. We calculate the annual exceedance probability curves and $95 \%$ confidence intervals for two measures of high-impact ETCs: minimum sea level pressure (SLP) and maximum wind speed. Only values that occur during the cold season (November-April) are considered. Exceedance curves for these quantities are also computed for consecutive, nonoverlapping 31-yr and 100-yr portions of FLOR to quantify the spread of 10-, 50-, 100-, 200-, and 500-yr return levels as would be estimated from records of comparable length to reanalysis and tide-gauge datasets, respectively.

For each year of the record, the lowest SLP values occurring within $500 \mathrm{~km}$ of The Battery measured along great circles are identified (Fig. 1). This region is chosen to contain average ETC positions from clustered SLP maps at the time of maximum storm surge at The Battery (see Fig. 2 in CB18). As a measure of intensity, annual minimum SLP values are subtracted from the global mean SLP, $1013.25 \mathrm{hPa}$; thus, the largest positive values correspond to the deepest ETCs. The annual exceedance probability for intensity values is displayed in Fig. 2a. The GEV curve corresponds well to the actual distribution of intensity values, although the largest $10-15$ events generally lie above the best-fit estimate, suggesting that the distribution of actual extreme SLP values has a fatter tail.

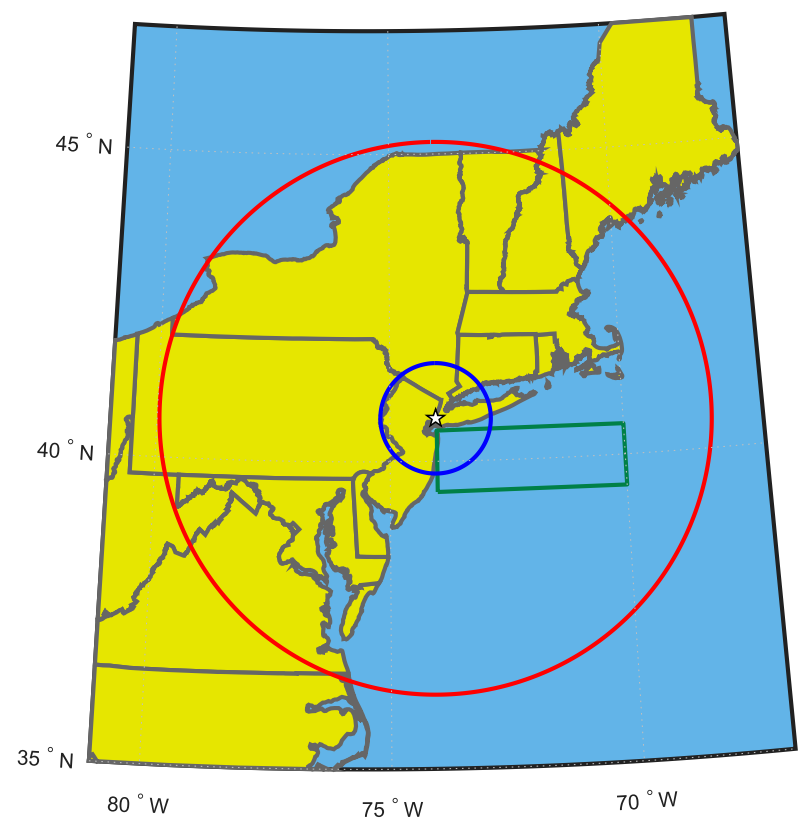

FIG. 1. Map of the study region over the northeast coast of the United States. The red circle specifies the $500-\mathrm{km}$ region over which the maximum intensity event is selected, the blue circle specifies the $100-\mathrm{km}$ region over which the maximum wind speed event is selected, and the green rectangle specifies the region over which the storm surge index is computed. The white star is the location of The Battery in New York City.

The median of GEV estimates determined from the 31-yr subsamples of the FLOR simulation (hereafter FLOR31) for a 10 -yr return level is $52.0 \mathrm{hPa}$, which is close to the value of $52.7 \mathrm{hPa}$ estimated from the full record. However, at return periods beyond the length of the FLOR31 subsamples, uncertainty in return level estimation increases. For example, the range of FLOR31 estimates of 10-yr return levels is $10.1 \mathrm{hPa}$, whereas the range increases to $28.0 \mathrm{hPa}$ and $66.9 \mathrm{hPa}$ for $100-$ and $500-\mathrm{yr}$ return periods, respectively. At a 100-yr return period, GEV analysis estimates a $95 \%$ confidence range of $5.1 \mathrm{hPa}$ for an intensity of $62.6 \mathrm{hPa}$ in the full FLOR record.

The narrowing of uncertainties in return levels determined from the longer record is not surprising, as the full record is longer than all the return periods examined $(10,50,100,200$, and 500 years $)$. But it is noteworthy that the FLOR31 estimates are systematically biased. At each return period examined, the median value of the FLOR31 return level estimates is lower than the return level estimated from the full FLOR sample. This underestimation is likely due to the fat tail of the actual distribution. The majority of FLOR31 subsamples do not include the most extreme events that lie above the fitted GEV distribution based on the full record. Thus, an underestimation of the return levels in the FLOR31 subsamples relative to those determined from the full 

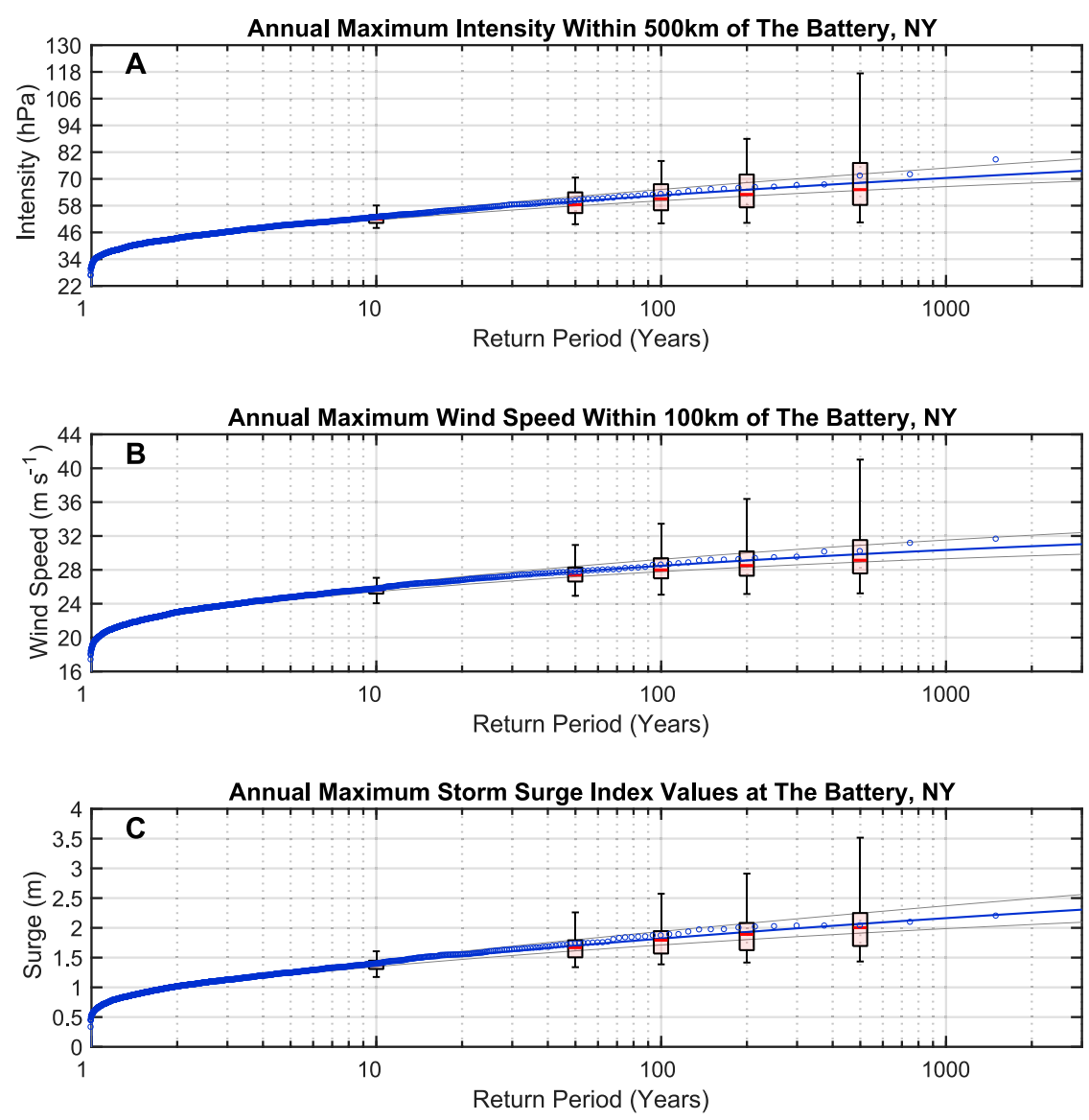

FIG. 2. FLOR annual exceedance probability curves of (a) maximum intensity within $500 \mathrm{~km}$ of The Battery (hPa), (b) maximum wind speed within $100 \mathrm{~km}$ of The Battery $\left(\mathrm{m} \mathrm{s}^{-1}\right)$, and (c) storm surge index values $(\mathrm{m})$ as a function of return period. Blue open circles represent annual maximum values, and blue curves are the fitted GEV distributions to these data points. Gray curves are $95 \%$ confidence intervals on fitted distributions. Box-and-whisker plots indicate the range of estimated values for FLOR 31-yr subsamples at designated return periods $(10,50,100,200$, and 500 years). The top and bottom of the boxes represent the 75 th and 25 th percentiles, respectively, and red lines within each box indicate the median value.

sample, which does contain these most extreme events, would be expected. Similar behavior is found for the estimates derived from the 100-yr FLOR subsamples, and therefore they will not be discussed further.

The distribution of annual maximum wind speeds within $100 \mathrm{~km}$ of The Battery (Fig. 2b) demonstrates similar behavior to that of SLP intensity values. All the actual wind speed values are located within the $95 \%$ confidence limits of the GEV fit determined from the full FLOR sample, although the GEV curve underestimates the most extreme wind speeds in the record. As observed for SLP extremes, the range of FLOR31 return levels for wind speed increases as the return period increases. The difference between the highest and lowest 10-yr return level is $3.0 \mathrm{~m} \mathrm{~s}^{-1}$, whereas the range for a 500 -yr return level is $15.8 \mathrm{~m} \mathrm{~s}^{-1}$. The median FLOR31 return levels are again consistently lower than the full record GEV curve.
A significant impact of ETCs near New York City is the storm surge produced. Storm surge potential of simulated systems is evaluated by applying a surge index developed by Roberts et al. (2015) for The Battery. This regression-based index assumes a linear combination of the local pressure perturbation of the sea level and surface wind stress components. Persistence of strong winds can augment surge height (Bernhardt and DeGaetano 2012), so the duration of wind stress over the region is included. Since our model output is 6hourly whereas the index was trained using 3-hourly data, we determine that a zonal integration period of $18 \mathrm{~h}$ and a meridional period of $24 \mathrm{~h}$ for wind stress components yield the best results at The Battery. The index is applied over a comparable region southeast of The Battery (Fig. 1). Hereafter, an estimated surge value is defined as a storm surge index (SSI). 
As in Figs. 2a and 2b, the spread of FLOR31 SSI values is wider at larger return periods, with a range over $2 \mathrm{~m}$ for subsample estimates of a 500 -yr event (Fig. 2c). Unlike wind and intensity distributions, the four largest SSI events lie along the GEV curve. The previous 15 events lie above the fit; however, all SSI values are within the 95\% confidence intervals. Median FLOR31 SSI return levels are lower than actual levels estimated from the full record, although the underestimation is small compared to that of intensity and wind distributions. This difference could be a result of an underprediction bias for the largest surge events using a regression-based index (Roberts et al. 2015).

The systematic underestimation of return levels determined from the short subsamples may have important implications for estimating extreme events in the real climate system. If the frequency distribution of FLOR ETCs resembles the distribution of actual ETCs in the region of interest (i.e., has a fatter tail than would be expected from GEV theory), then it would be likely that the return levels of ETC-related extremes of SLP, wind speed, and storm surge estimated from the observed climate record would also be underestimated, with a concomitant overestimation of return periods.

\section{Characteristics of selected gray swans}

We adopt the phrase "grey swans" (Lin and Emanuel 2016) to describe high-impact ETCs that have not been observed but are physically possible. In this section, we describe some broad synoptic characteristics of several cold-season gray swans that would have high impacts at New York: the lowest pressure event within $500 \mathrm{~km}$ of The Battery, the highest wind event within $100 \mathrm{~km}$ of the same location, and the second largest SSI event from the full FLOR record. [For technical reasons involving the failure of automated postprocessing of certain variables, we cannot analyze the largest SSI event $(2.19 \mathrm{~m})$ from the record because upper-level atmospheric circulation variables are unavailable for that portion of the FLOR simulation.] Instantaneous values of upper-level circulation variables were not available from any portion of the run. Thus the analysis employs daily averages, which we determine to be sufficient in resolving general patterns and features.

The gray swans identified over the 1505 -yr record are considerably stronger than their observed counterparts in CFSR as well as in the ECMWF atmospheric reanalysis of the twentieth century (ERA-20C; Poli et al. 2016). ERA-20C has a lower spatial resolution than CFSR $(125 \mathrm{~km})$, but a longer record spanning 1900 2010. The lowest pressure event in FLOR is $62 \%$ deeper than CFSR and $48 \%$ deeper than ERA-20C, the highest wind event is $4 \%$ greater than CFSR and $35 \%$ greater than ERA-20C, and the second largest SSI value is $34 \%$ higher than CFSR and 26\% higher than ERA-20C.

The lowest SLP value within $500 \mathrm{~km}$ of The Battery is associated with a March ETC in model year 1307. An examination of upper-level circulation for select days prior to the time of lowest central pressure shows that the ETC formed from the phasing of two troughs. Ridging in Alaska and northwest Canada on 4 March was associated with a downstream shortwave trough in the northern branch of the 500-hPa flow (Fig. 3a). This trough phased with a second trough in the southern branch propagating from California, and the resulting feature extended over the entire North American continent by 6 March (Fig. 3b). A 500-hPa geopotential height cutoff low formed in the region of cyclone intensification over the northeastern United States on 9 March, which deepened by $240 \mathrm{~m}$ in $24 \mathrm{~h}$ (Figs. 3c,d). The surface cyclone deepened explosively to $934.9 \mathrm{hPa}$, intensifying by more than $55 \mathrm{hPa}$ over $24 \mathrm{~h}$ (Fig. 4). This rapid development produced an intense pressure gradient immediately south of the ETC center. The highest $10-\mathrm{m}$ wind speeds, which are greater than hurricaneforce, are located in this region of the storm.

The highest wind event within $100 \mathrm{~km}$ of The Battery occurred in December of model year 996 and also developed from the phasing of a shortwave trough near California with a trough to the north (Figs. 3e,f). On 2 December, a trough developed at $130^{\circ} \mathrm{W}$ with a jet streak to the west, which amplified deepening (Fig. 3e). As the trough progressed eastward over the Rocky Mountains, it flattened a prevailing ridge and merged with the northern trough (Fig. 3f). By 7 December, the surface cyclone propagated along the northeast coast, encountering an anticyclone over Maine beneath a ridge at $500 \mathrm{hPa}$ (Fig. 3g). These elements formed a strong pressure gradient, which produced nearly hurricane-force winds at $31.6 \mathrm{~m} \mathrm{~s}^{-1}$ (Fig. 5). For over $36 \mathrm{~h}$, the prevailing $10-\mathrm{m}$ wind direction near The Battery possessed an easterly component. This orientation, strength, and location of winds generated an SSI of $1.56 \mathrm{~m}$.

The second largest SSI event at The Battery reached $2.09 \mathrm{~m}$, occurring in November of model year 780. This system featured greater than storm-force east-northeasterly winds $6 \mathrm{~h}$ preceding the time of the maximum index value on 3 November (Fig. 6). SSI values remained above $1 \mathrm{~m}$ during this period, which is the level at which a coastal flood warning is issued by the National Weather Service (Colle et al. 2010). The SSI event encountered a strong anticyclone to the north, producing a steep pressure gradient in the region and reducing the rate of propagation to a 12-h average of $4.1 \mathrm{~m} \mathrm{~s}^{-1}$, which is slower than the lowest average speed 


\section{March 1307 Event December 996 Event November 780 Event}

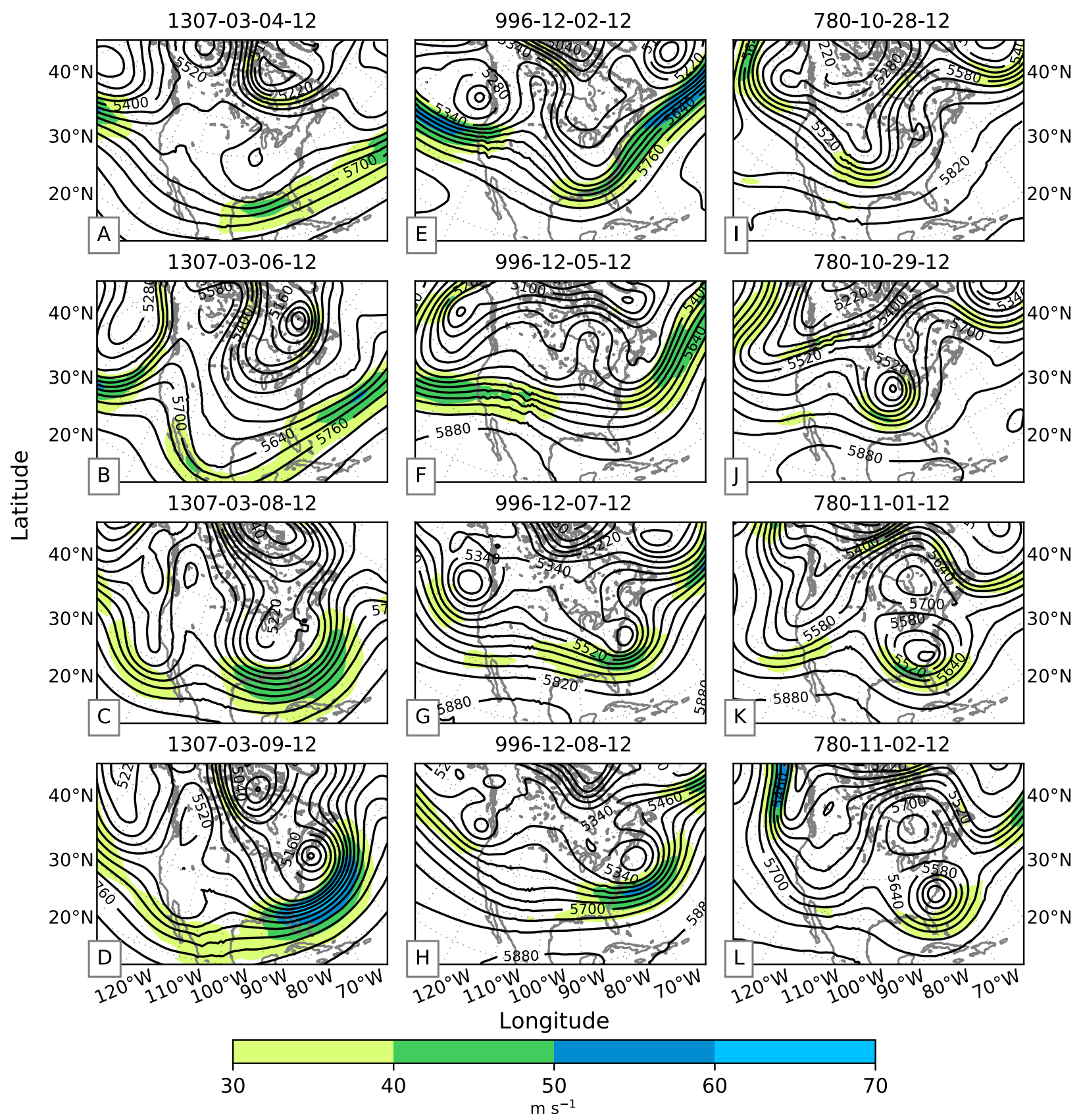

FIG. 3. Daily average atmospheric circulation at $500 \mathrm{hPa}$ for select days associated with (a)-(d) the lowest pressure event, (e)-(h) the highest wind event, and (i)-(l) the second largest storm surge index event near The Battery (see Fig. 1). Solid black contours represent geopotential height $(\mathrm{m})$, and shaded regions are wind speeds at $500 \mathrm{hPa}\left(\mathrm{m} \mathrm{s}^{-1}\right)$. Note that maps increase in time from top to bottom, but intervals between maps differ.

for clustered ETC-driven surge events in the northeastern United States $\left(\mathrm{CB} 18 ; 6.6 \mathrm{~m} \mathrm{~s}^{-1}\right)$. The strength of these features is evident at $500 \mathrm{hPa}$, where large geopotential height anomalies and a cutoff low are present over five days prior to the time of the maximum SSI value (Fig. 3j). The development of a strong ridge in the northern branch of the flow leads to the formation of a persistent Rex (or "high-over-low") block (Rex 1950) on 1 November (Fig. 3k), with 500-hPa height anomalies of more than $480 \mathrm{~m}$ near Hudson Bay. This block persists for over four days, maintaining a strong pressure gradient between high pressure over eastern Canada 

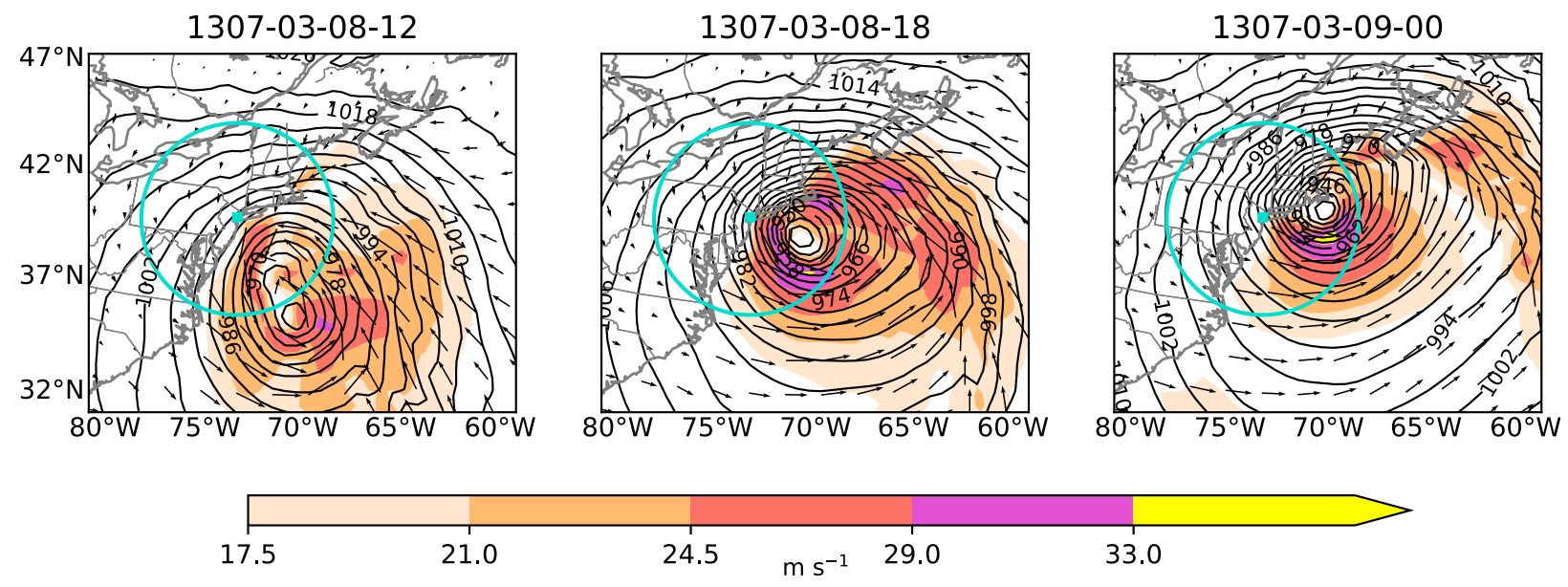

FIG. 4. Contoured SLP maps of the deepest simulated extratropical cyclone during the cold season within $500 \mathrm{~km}$ of The Battery (turquoise). Vector overlay and shaded regions are $10-\mathrm{m}$ wind speeds categorized according to the Beaufort scale wherein $17.5 \mathrm{~m} \mathrm{~s}{ }^{-1}$ is gale, $21.0 \mathrm{~m} \mathrm{~s}^{-1}$ is strong gale, $24.5 \mathrm{~m} \mathrm{~s}^{-1}$ is storm, $29.0 \mathrm{~m} \mathrm{~s}^{-1}$ is violent storm, and $>33.0 \mathrm{~m} \mathrm{~s}^{-1}$ is hurricane-force wind.

and a broad cyclone east of the Carolinas (Fig. 31). The associated pressure gradient resulted in gale-force onshore winds in the New York Bight for more than $24 \mathrm{~h}$. CB18 found that synoptic characteristics such as those found in this event were associated with the majority of the largest observed ETC-driven surge events at The Battery.

\section{Fidelity of the model}

The utility of such simulations for quantitatively assessing the probabilities of extreme ETC impacts depends upon model fidelity. In this section, we compare simulated and observed ETC properties in more detail through a comparison with an atmospheric reanalysis product, CFSR (Saha et al. 2010). CFSR provides continuous data for the period 1979-2009 and was used to train and test the storm surge index (Roberts et al. 2015). The native atmospheric resolution is $38 \mathrm{~km}$ (T382), but for comparable horizontal resolution to FLOR we use output at $0.5^{\circ}$. Reanalyses have been used previously to evaluate models with respect to simulated cyclones (Bengtsson et al. 2009; Catto et al. 2011). CFSR compares well with other reanalysis products in the spatial distribution of cyclones (Hodges et al. 2003) and propagation of intense ETCs in the Northern Hemisphere (Hodges et al. 2011). Also, CFSR matches well with upper percentiles of buoy and altimetry wind data, suggesting that CFSR is more useful than other reanalysis products for analyzing extremes (Stopa and Cheung 2014). Although CFSR is ultimately chosen, we note that a preliminary analysis of climatological wind speeds over the northwestern Atlantic Ocean shows substantial differences among reanalyses. Ascertaining
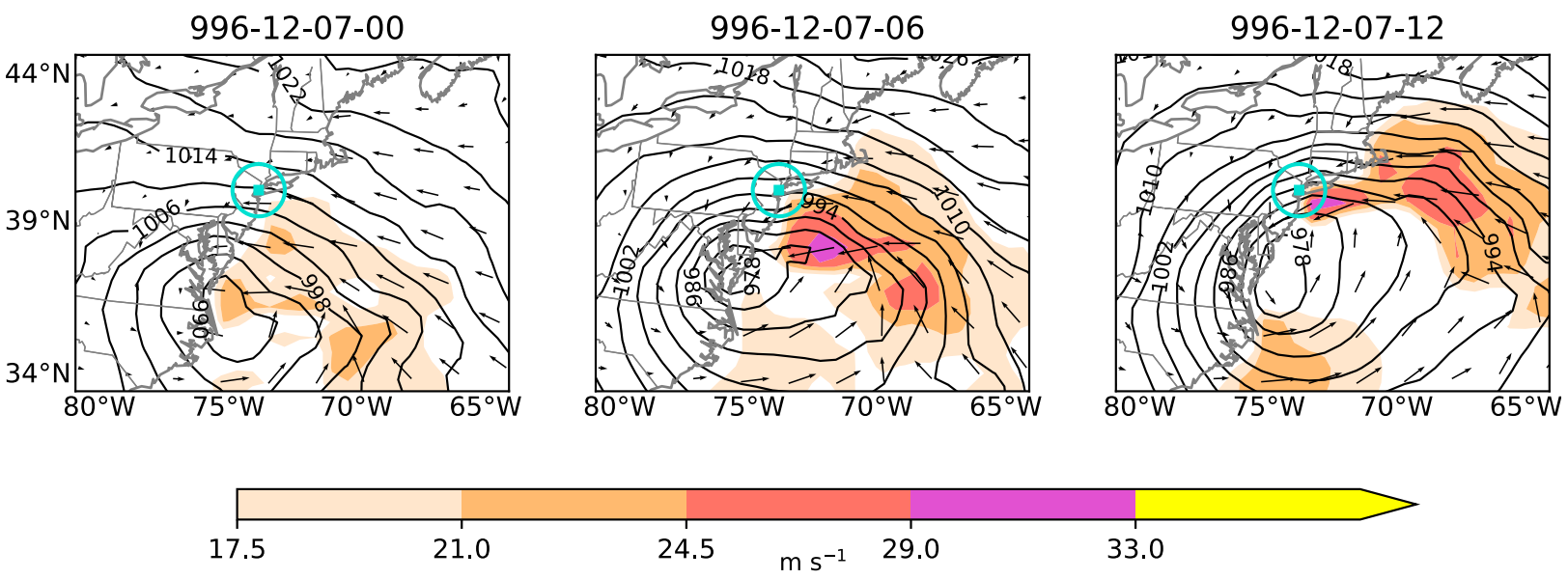

FIG. 5. As in Fig. 4, but for a simulated extratropical cyclone associated with the highest wind speed during the cold season within $100 \mathrm{~km}$ of The Battery (turquoise). 
780-11-02-12

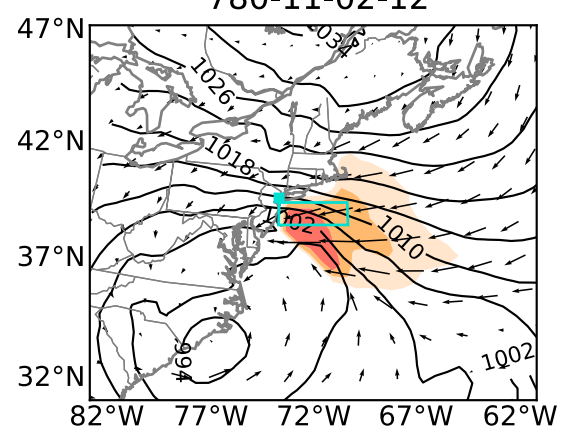

780-11-02-18

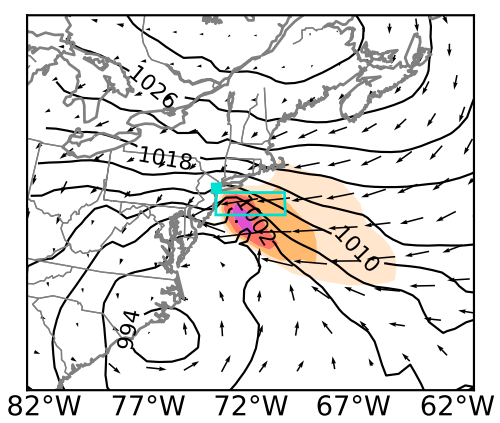

780-11-03-00

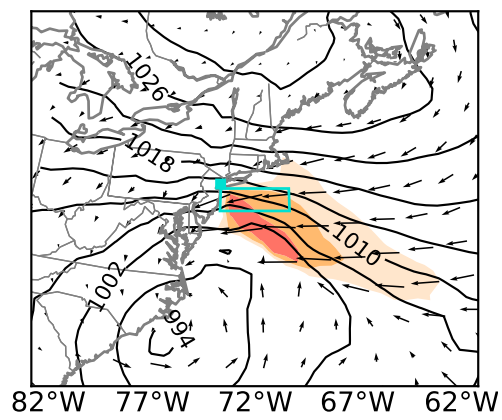

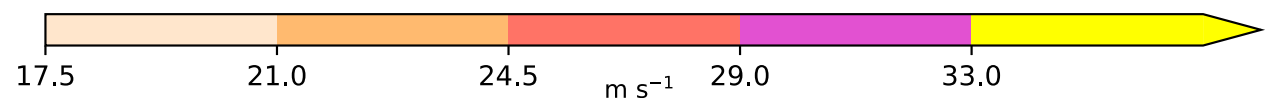

FIG. 6. As in Fig. 5, but for a simulated extratropical cyclone associated with the second largest SSI during the cold season calculated over a region southeast of The Battery (turquoise). The SSI values from left to right are 1.57, 2.02, and $2.09 \mathrm{~m}$.

why these differences exist would be valuable as they can affect the utility of reanalysis products for evaluating the fidelity of a model.

Figure 7 displays spatial cyclogenesis rates and feature densities for CFSR and FLOR. As in Hoskins and Hodges (2002), feature density is the number of 6-hourly cyclone centers passing through a prescribed grid box, even if the centers belong to the same ETC. This gives more weight to slowly moving cyclones, which have been associated with high-impact events in the northeastern United States (e.g., the "Perfect Storm" of October 1991). Spatial densities are normalized by the total record length (1505 or 31 years).

Comparisons of cyclogenesis and feature densities indicate similarities between CFSR and FLOR. Both CFSR and FLOR exhibit the highest frequency of cyclone development along the East Coast of the United States and extending along the $40^{\circ} \mathrm{N}$ parallel (Figs. $7 \mathrm{a}, \mathrm{c}$ ). Feature densities are largest in the northwestern Atlantic Ocean including the Bay of Fundy, as well as a localized maximum over Hudson Bay (Figs. 7b,d). Since the FLOR record is considerably longer than CFSR, model output is also subdivided into consecutive, nonoverlapping segments of 31 years to compute the spread across these subsamples (FLOR31, as in section 3). CFSR feature densities are within one standard deviation of FLOR values, whereas ETC frequencies differ by approximately three standard deviations for the region of highest cyclogenesis rates east of Cape Hatteras.

To further diagnose the inconsistency between simulated and observed ETCs, metrics of storm intensity for cold-season ETCs within $500 \mathrm{~km}$ of The Battery are evaluated. For each 31-yr period of FLOR, minimum central pressures and maximum $10-\mathrm{m}$ wind speeds associated with ETCs are binned in intervals of $4 \mathrm{hPa}$ or $2 \mathrm{~m} \mathrm{~s}^{-1}$ to obtain the spread of subsample frequencies, which are then compared against CFSR frequencies. In over $50 \%$ of the bins, the frequency of CFSR wind speeds lies within the 25th-75th percentile range of FLOR31 values (Fig. 8a). However, at several higher wind speed intervals such as 24-26 $\mathrm{m} \mathrm{s}^{-1}$ and $28-30 \mathrm{~m} \mathrm{~s}^{-1}$, CFSR values lie outside the spread of the FLOR31 subsamples. Similarly, the frequencies of observed minimum pressures are within the range of FLOR31 values for ETCs with central pressures greater than $990 \mathrm{hPa}$, but are lower than the range of FLOR31 frequencies for values less than $980 \mathrm{hPa}$ (Fig. 8b). This suggests that although the longer record of FLOR provides more examples of ETCs in each wind and pressure interval, as well as values that are more extreme than observed, the model simulates too many intense ETCs.

Because the storm surge index is a combination of central pressure and low-level wind values, biases in the simulation of these quantities may also affect SSI values. Therefore, the distribution of SSI values for the entire FLOR simulation is compared to the distributions from CFSR and ERA-20C. CFSR and ERA-20C data were sampled at 6-h intervals $(0000,0600,1200$, and 1800 UTC) for consistency with FLOR output. The additional years of data in the ERA-20C record result in a greater range of SSI values than CFSR, but the distributions are otherwise similar (Fig. 9). The spread of ERA-20C SSI values between the 1st and 99th percentiles is $0.96 \mathrm{~m}$ with a maximum value of $1.65 \mathrm{~m}$, and the spread for CFSR is $0.86 \mathrm{~m}$ with a maximum value is $1.56 \mathrm{~m}$. The SSI distribution for FLOR exhibits longer tails for both positive and negative values, and the maximum index is $2.19 \mathrm{~m}$. However, the spread between the 1st and 99th percentiles is wider than observational datasets, with a range of $1.3 \mathrm{~m}$. The longer FLOR record contains a greater number of large SSI values, but the 
FLOR Cyclogenesis Frequency

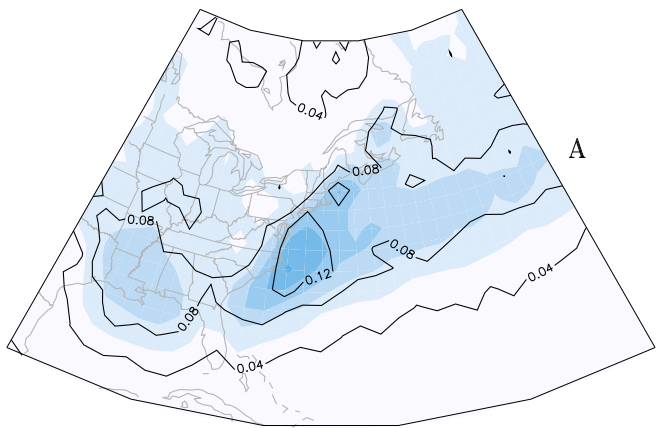

CFSR Cyclogenesis Frequency

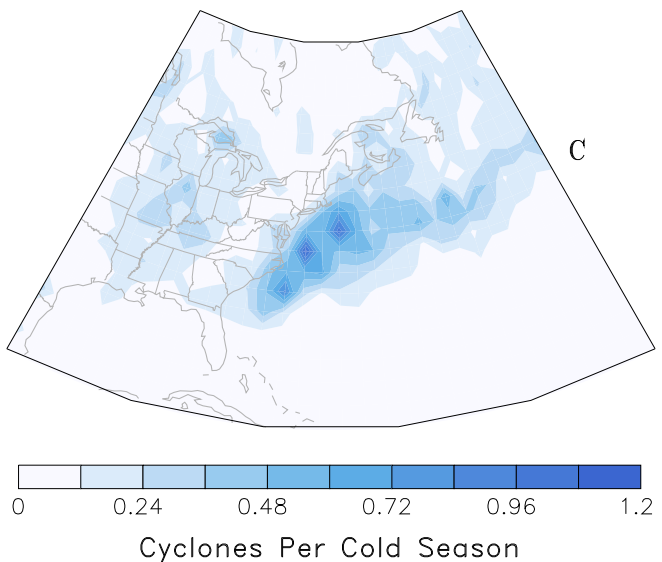

FLOR Cyclone Feature Frequency

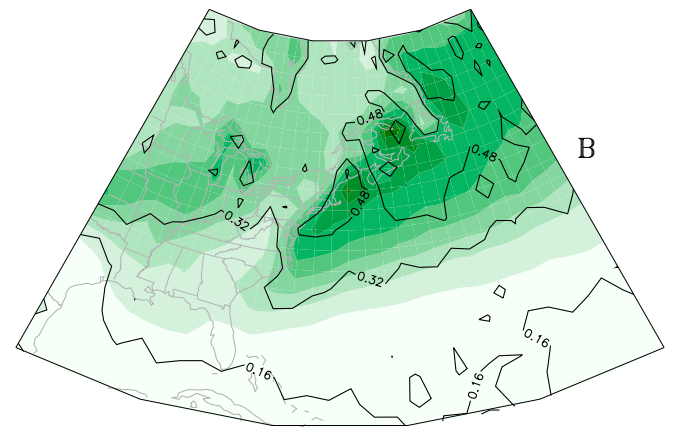

CFSR Cyclone Feature Frequency

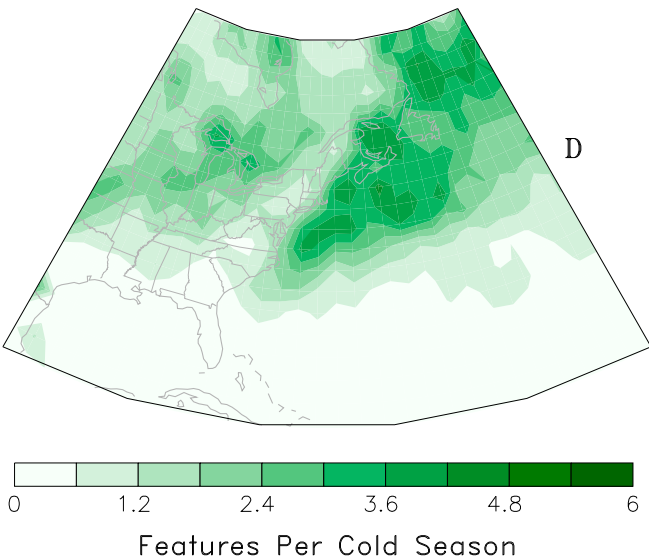

FIG. 7. (a),(b) FLOR and (c),(d) CFSR cyclogenesis and feature densities per cold season normalized by record length (1505 and 31 years, respectively). Black contours represent one standard deviation spread over 31-yr subsets [contoured at intervals of 0.04 in (a) and 0.16 in (b)]. Feature density measures the number of cyclone centers passing through the region.

larger spread of the distribution suggests that FLOR simulates more extreme SSI events, which is consistent with the apparent biases in the variables used to compute the index (10-m wind speed and SLP).

Vecchi et al. (2014) documented a cold bias in FLOR SSTs, which may affect the quantities analyzed in this study. To test the effects, we use an available 500-yr 1990 control simulation using a flux-adjusted version of the model (FLOR-FA). FLOR-FA modifies momentum, freshwater, and enthalpy fluxes between the ocean and atmosphere so that the long-term climatology of simulated SSTs resembles observations over the period 1979-2012. FLOR-FA was built using methodology outlined in Magnusson et al. (2013) and applied globally: the model uses sea surface temperatures from the HadISST.v1 dataset, climatological sea surface salinity is taken from the World Ocean Atlas 2005 (Antonov et al. 2006), and surface zonal and meridional wind stresses are extracted from ERA-Interim. A detailed description of the process is also included in Vecchi et al. (2014).
When compared with CFSR, normalized cyclone statistics and frequency distributions of intensity metrics in FLOR-FA show a reduced bias relative to FLOR, but substantial biases remain. As an example of the reduction in bias, annual maximum SLP anomalies in FLOR, FLOR-FA, and CFSR are displayed as a function of return period in Fig. 10. Compared to FLOR events, FLOR-FA return values are somewhat closer to those of CFSR, but large differences remain, especially at shorter return periods. A more realistic SST distribution improved the simulation of ETC intensities, but there are still differences in the distribution and magnitude of extreme values when compared to CFSR; this suggests that a systematic bias in the simulation of ETCs exists in FLOR with or without flux adjustment.

\section{Summary and discussion}

One of the novel aspects of this work is the use of a long control simulation ( $>1500$ years) from a coupled 
10-m Wind Speed Frequency for Cold-Season Storms Within $500 \mathrm{~km}$ of The Battery

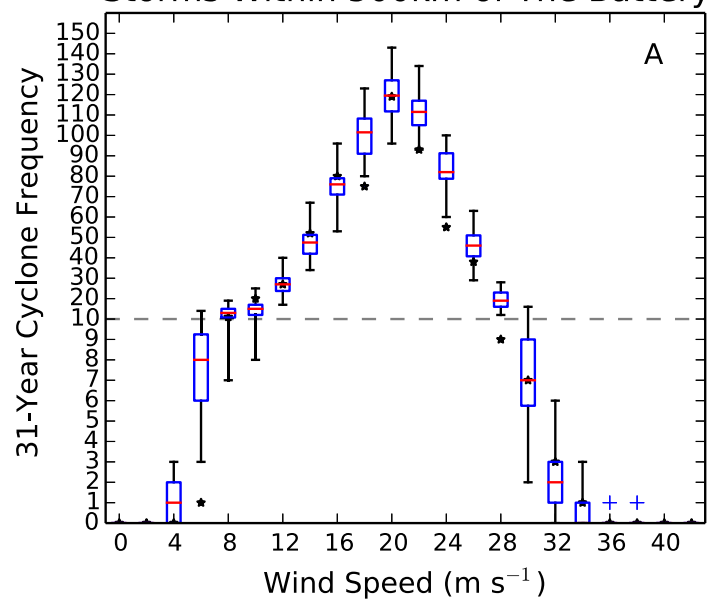

Sea Level Pressure Frequency for Cold-Season Storms Within $500 \mathrm{~km}$ of The Battery

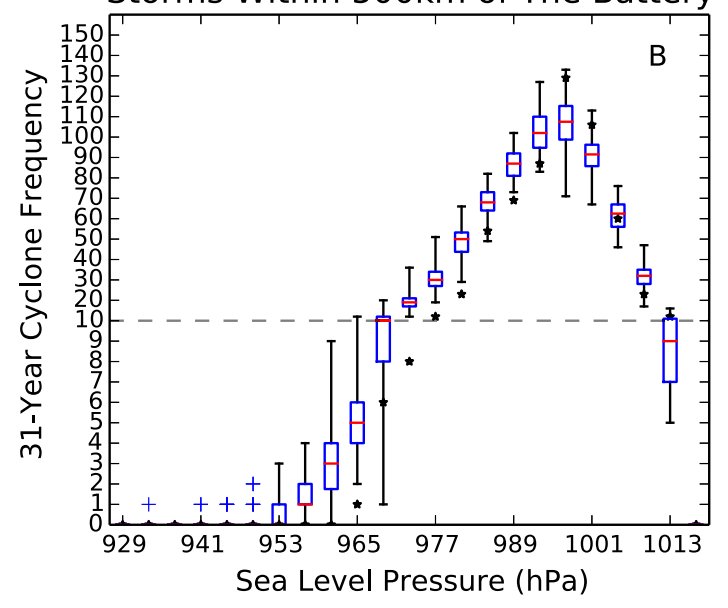

FIG. 8. Box-and-whisker plots of (a) maximum 10-m wind speed values $\left(\mathrm{m} \mathrm{s}^{-1}\right)$ and (b) minimum sea level pressure values $(\mathrm{hPa})$ within $500 \mathrm{~km}$ of The Battery for cold-season storms across FLOR 31-yr subsamples. Black asterisks indicate CFSR values. The top and bottom of the boxes represent the 75th and 25th percentiles, respectively, and red lines within each box indicate the median value. Whiskers span the range of data (from minimum to maximum). Numbers along the horizontal axis refer to the minimum boundary of the bin interval, e.g., the boxplot of wind speed frequency centered on $28 \mathrm{~m} \mathrm{~s}^{-1}$ is for wind speeds in the range [28-30). Note: intervals differ below the dashed line to magnify lower frequency behavior.

atmosphere-ocean general circulation model with $50-\mathrm{km}$ atmospheric resolution to examine the frequency distribution of extreme ETC impacts. To our knowledge, this work is the first such application of a coupled climate model for this purpose. Although there are biases in metrics of coldseason ETC development and intensity, we demonstrate that a long model simulation could be useful for a statistical assessment of extreme ETC characteristics and an examination of rare but impactful events that may occur.

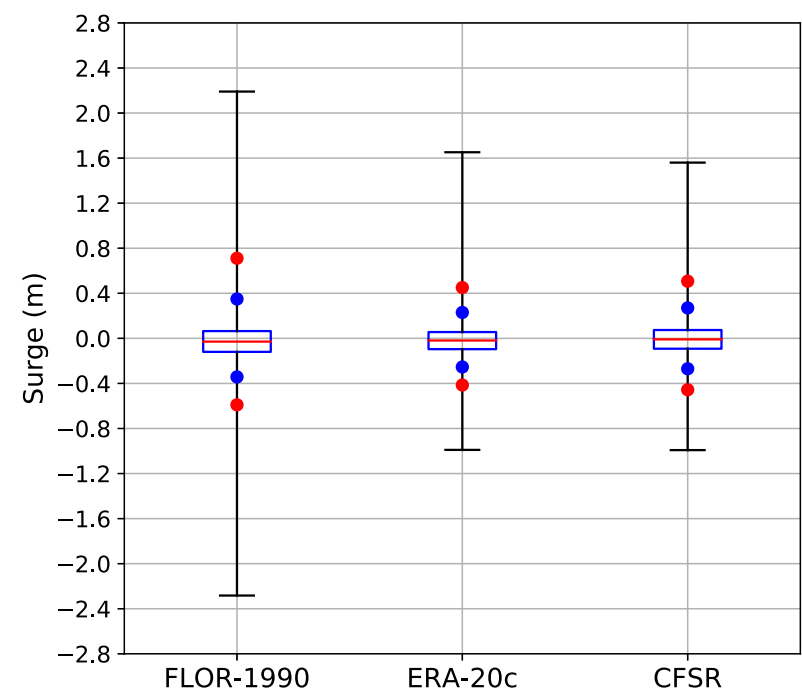

FIG. 9. Box-and-whisker plots of storm surge indices $(\mathrm{m})$ for all 6-hourly data from FLOR, ERA-20c, and CFSR. The top and bottom of the boxes represent the 75 th and 25 th percentiles, respectively, and red lines within each box indicate the median value. Blue circles indicate 5th and 95th percentiles, and red circles specify surge values at the 1 st and 99th percentiles. Whiskers span the range of data (from minimum to maximum).

Results from an extreme value analysis illustrate that there is a greater uncertainty in estimates of large $(>50 \mathrm{yr})$ return levels for high wind and intensity events near The Battery using 31-yr subsamples of the GFDL FLOR coupled model than using the full record. Although this greater uncertainty is not unexpected, the wide range of return levels also suggests the difficulty in predicting the occurrence rate of high-impact ETCs from shorter records. This has been addressed in previous work examining other extreme climate events in the modeling suite employed here including extreme precipitation events on land (van der Wiel et al. 2017) and Mississippi floods (van der Wiel et al. 2018). Perhaps more notable, the tendency for return levels to be underestimated when using short (i.e., $31 \mathrm{yr}$ ) samples has important implications for estimates of ETC impacts using observations. If the distributions of annual maximum wind, intensity, or surge index in the real climate system resemble the model, then statistical analyses using historical records currently available may be underestimating the actual frequency of extreme events.

The full record of FLOR includes intense high-impact ETCs that may not be present in a sample of historical length. Examining a few select FLOR cases, the most extreme ETCs are accompanied by unusually low SLP $(934.9 \mathrm{hPa})$, hurricane-force winds $\left(34.5 \mathrm{~m} \mathrm{~s}^{-1}\right)$, and a storm surge index value more than $35 \%$ larger than the largest computed from reanalysis. ETC events such as these would have potentially severe impacts for coastal regions in their proximity. 


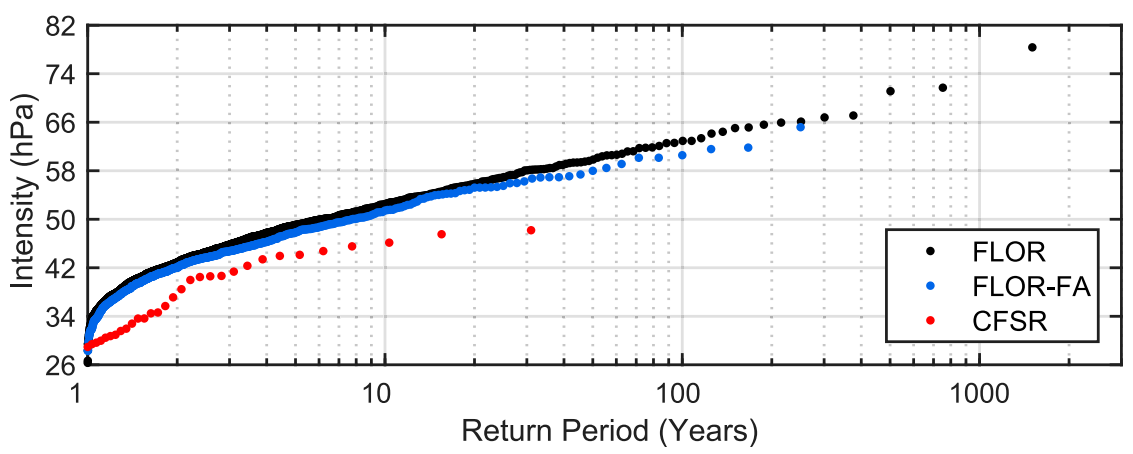

FIG. 10. Maximum annual cold-season intensity (hPa) within $500 \mathrm{~km}$ of The Battery as a function of return period for FLOR (black), FLOR-FA (blue), and CFSR (red). The rightmost points indicate the lengths of the records.

Comparing the climatological distribution of ETCs in FLOR with reanalysis reveals important similarities and differences. The highest frequency of cold-season cyclone development and propagation occurs in the northwestern Atlantic Ocean in both FLOR and CFSR, but the magnitude of the observed cyclogenesis density is nearly three standard deviations higher than the mean FLOR density. Also, minimum SLP and maximum wind speed values associated with simulated ETCs are too frequent in higher intensity ranges compared to CFSR cyclones. Previous work comparing CFSR surface winds with buoys over the North Atlantic identified a slight overestimation in wind magnitude (Stopa and Cheung 2014). This suggests that the differences in ETC intensity between FLOR and CFSR are primarily a result of a model bias in storm strength. Employing a version of FLOR that forces SSTs to be more realistic improves some estimates, but there are still substantial biases present. Using the results from this model for a robust quantitative assessment of high-impact ETC risks is precluded by the biases we have found. Nonetheless, these results demonstrate that multicentury model runs, should they be of high enough fidelity, could be used to produce more accurate assessments of return levels and return periods for extreme ETCs and their impacts. Thus this study can be regarded as a proof of concept, the implementation of which will require models with even greater realism. As advancements are made in the simulated representation of the climate system and longer records are produced, our methodology can be applied to more accurately assess risks associated with high-impact ETCs. More reliable estimates of storm surge risk would likely require the use of a hydrodynamic surge model, which will be a target of future work.

Although not addressed in the scope of this work, changes in future climate and mean sea level will affect the frequency of high-impact ETCs. By applying the regression surge index to several models from phase 5 of the Coupled Model Intercomparison Project, and the
CESM large ensemble, Roberts et al. (2017) observe a poleward shift and intensification of ETCs with the potential to produce a large storm surge. Seasonal changes in atmospheric circulation features such as the midlatitude jet stream, which has been shown to affect storm track variability (Eichler and Higgins 2006; Athanasiadis et al. 2010), have the potential to alter storm surge risks at specific locations. Also, large storm surge-producing ETCs in the northeastern United States occur preferentially during certain modes of climate variability (i.e., negative NAO, AO) and synoptic-scale circulation patterns, as determined in CB18. Whether these circulation features respond to a changing climate will affect ETC propagation and associated impacts on different time scales. Ongoing improvements in climate models, including increased horizontal and vertical resolution to better capture mesoscale features within intense ETCs, will improve our ability to quantify the risks posed by infrequent and impactful events in a warming climate.

Acknowledgments. The authors thank Lucas Harris and Hiroyuki Murakami for their assistance with the GFDL cyclone tracker, and Hiroyuki Murakami and Xiaosong Yang for providing comments on the manuscript. The authors also acknowledge four anonymous reviewers for suggestions that greatly improved this manuscript. Advice on computational matters was provided by Bryan Raney. This research was supported by the William H. Greenberg Fellowship from Rutgers University and the National Science Foundation Earth System Modeling Program (OCE1049088).

\section{REFERENCES}

Antonov, J. I., R. A. Locarnini, T. P. Boyer, A. V. Mishonov, and H. E. Garcia, 2006: Salinity. Vol. 2, World Ocean Atlas 2005, NOAA Atlas NESDIS 62, 182 pp. 
Athanasiadis, P. J., J. M. Wallace, and J. J. Wettstein, 2010: Patterns of wintertime jet stream variability and their relation to the storm tracks. J. Atmos. Sci., 67, 1361-1381, https://doi.org/ 10.1175/2009JAS3270.1.

Bengtsson, L., K. I. Hodges, and N. Keenlyside, 2009: Will extratropical storms intensify in a warmer climate? J. Climate, 22, 2276-2301, https://doi.org/10.1175/2008JCLI2678.1.

Bernhardt, J. E., and A. T. DeGaetano, 2012: Meteorological factors affecting the speed of movement and related impacts of extratropical cyclones along the U.S. East Coast. Nat. Hazards, 61, 1463-1472, https://doi.org/10.1007/s11069-011-0078-0.

Catalano, A. J., and A. J. Broccoli, 2018: Synoptic characteristics of surge-producing extratropical cyclones along the northeast coast of the United States. J. Appl. Meteor. Climatol., 57, 171184, https://doi.org/10.1175/JAMC-D-17-0123.1.

Catto, J. L., L. C. Shaffrey, and K. I. Hodges, 2011: Northern Hemisphere extratropical cyclones in a warming climate in the HiGEM high-resolution climate model. J. Climate, 24, 53365352, https://doi.org/10.1175/2011JCLI4181.1.

Coles, S., 2001: An Introduction to Statistical Modeling of Extreme Values. Springer, 208 pp.

Colle, B. A., K. Rojowsky, and F. Buonaito, 2010: New York City storm surges: Climatology and an analysis of the wind and cyclone evolution. J. Appl. Meteor. Climatol., 49, 85-100, https://doi.org/10.1175/2009JAMC2189.1.

_- Z. Zhang, K. A. Lombardo, E. Chang, P. Liu, and M. Zhang, 2013: Historical evaluation and future prediction of eastern North American and western Atlantic extratropical cyclones in the CMIP5 models during the cool season. J. Climate, 26, 6882-6903, https://doi.org/10.1175/ JCLI-D-12-00498.1.

Delworth, T. L., and Coauthors, 2006: GFDL's CM2 global coupled climate models. Part 1: Formulation and simulation characteristics. J. Climate, 19, 643-674, https://doi.org/10.1175/ JCLI3629.1.

_- and Coauthors, 2012: Simulated climate and climate change in the GFDL CM2.5 high-resolution coupled climate model. J. Climate, 25, 2755-2781, https://doi.org/10.1175/ JCLI-D-11-00316.1.

Eichler, T., and W. Higgins, 2006: Climatology and ENSO-related variability of North American extratropical cyclone activity. J. Climate, 19, 2076-2093, https://doi.org/10.1175/JCLI3725.1.

Emanuel, K., S. Ravela, E. Vivant, and C. Risi, 2006: A statistical deterministic approach of hurricane risk assessment. Bull. Amer. Meteor. Soc., 87, 299-314, https://doi.org/10.1175/ BAMS-87-3-299.

Gulev, S. K., O. Zolina, and S. Grigoriev, 2001: Extratropical cyclone variability in the Northern Hemisphere winter from the NCEP/NCAR reanalysis data. Climate Dyn., 17, 795-809, https://doi.org/10.1007/s003820000145.

Hall, T., and E. Yonekura, 2013: North American tropical cyclone landfall and SST: A statistical model study. J. Climate, 26, 8422-8439, https://doi.org/10.1175/JCLI-D-12-00756.1.

— , and J. F. Booth, 2017: SynthETC: A statistical model for severe winter storm hazard on eastern North America. J. Climate, 30, 5329-5343, https://doi.org/10.1175/JCLI-D-16-0711.1.

Harris, L. M., S.-J. Lin, and C. Tu, 2016: High-resolution climate simulations using GFDL HiRAM with a stretched global grid. J. Climate, 29, 4293-4314, https://doi.org/10.1175/ JCLI-D-15-0389.1.

Hodges, K. I., B. J. Hoskins, J. Boyle, and C. Thorncroft, 2003: A comparison of recent reanalysis datasets using objective feature tracking: Storm tracks and tropical easterly waves. Mon.
Wea. Rev., 131, 2012-2037, https://doi.org/10.1175/1520-0493 (2003)131<2012:ACORRD>2.0.CO;2.

-_, R. W. Lee, and L. Bengtsson, 2011: A comparison of extratropical cyclones in recent reanalyses ERAInterim, NASA MERRA, NCEP CFSR, and JRA-25. J. Climate, 24, 4888-4906, https://doi.org/10.1175/ 2011JCLI4097.1.

Hoskins, B. J., and K. I. Hodges, 2002: New perspectives on the Northern Hemisphere winter storm tracks. J. Atmos. Sci., 59, 1041-1061, https://doi.org/10.1175/1520-0469(2002)059<1041: NPOTNH $>2.0 . \mathrm{CO} ; 2$.

Kocin, P., P. Schumacher, R. Morales, and L. Uccellini, 1995: Overview of the 12-14 March 1993 Superstorm. Bull. Amer. Meteor. Soc., 76, 165-182, https://doi.org/10.1175/1520-0477 (1995)076<0165:OOTMS >2.0.CO;2.

Lin, N., and K. Emanuel, 2016: Grey swan tropical cyclones. Nat. Climate Change, 6, 106-111, https://doi.org/10.1038/ nclimate2777.

$\_, \ldots$, M. Oppenheimer, and E. Vanmarcke, 2012: Physically based assessment of hurricane surge threat under climate change. Nat. Climate Change, 2, 462-467, https://doi.org/ 10.1038/nclimate1389.

Magnusson, L., M. Alonso-Balmaseda, S. Corti, F. Molteni, and T. Stockdale, 2013: Evaluation of forecast strategies for seasonal and decadal forecasts in presence of systematic model errors. Climate Dyn., 41, 2393-2409, https://doi.org/10.1007/ s00382-012-1599-2.

Murakami, H., and Coauthors, 2015: Simulation and prediction of category 4 and 5 hurricanes in the high-resolution GFDL HiFLOR coupled climate model. J. Climate, 28, 9058-9079, https://doi.org/10.1175/JCLI-D-15-0216.1.

Poli, P., and Coauthors, 2016: ERA-20C: An atmospheric reanalysis of the twentieth century. J. Climate, 29, 4083-4097, https://doi.org/10.1175/JCLI-D-15-0556.1.

Prescott, P., and A. T. Walden, 1980: Maximum-likelihood estimation of the parameters of the generalized extreme-value distribution. Biometrika, 67, 723-724, https://doi.org/10.1093/ biomet/67.3.723.

Raible, C. C., P. M. Della-Marta, C. Schwierz, H. Wernli, and R. Blender, 2008: Northern Hemisphere extratropical cyclones: A comparison of detection and tracking methods and different reanalyses. Mon. Wea. Rev., 136, 880-897, https://doi.org/ 10.1175/2007MWR2143.1.

Rex, D. F., 1950: Blocking action in the middle troposphere and its effect upon regional climate. Tellus, 2, 196-211, https://doi.org/ 10.1111/j.2153-3490.1950.tb00331.x.

Roberts, K. J., B. A. Colle, N. Georgas, and S. B. Munch, 2015: A regression-based approach for cool-season storm surge predictions along the New York-New Jersey coast. J. Appl. Meteor. Climatol., 54, 1773-1791, https://doi.org/10.1175/ JAMC-D-14-0314.1.

,$- \ldots$, and N. Korfe, 2017: Impact of simulated twenty-firstcentury changes in extratropical cyclones on coastal flooding at The Battery, New York City. J. Appl. Meteor. Climatol., 56 , 415-432, https://doi.org/10.1175/JAMC-D-16-0088.1.

Saha, S., and Coauthors, 2010: The NCEP Climate Forecast System Reanalysis. Bull. Amer. Meteor. Soc., 91, 1015-1057, https:// doi.org/10.1175/2010BAMS3001.1.

Smith, C. D., 1950: The destructive storm of November 25-27, 1950. Mon. Wea. Rev., 78, 204-209, https://doi.org/10.1175/ 1520-0493(1950)078<0204:TDSON >2.0.CO;2.

Stopa, J. E., and K. F. Cheung, 2014: Intercomparison of wind and wave data from the ECMWF Reanalysis Interim and the 
NCEP Climate Forecast System Reanalysis. Ocean Modell., 75, 65-83, https://doi.org/10.1016/j.ocemod.2013.12.006.

van der Wiel, K., and Coauthors, 2017: Rapid attribution of the August 2016 flood-inducing extreme precipitation in south Louisiana to climate change. Hydrol. Earth Syst. Sci., 21, 897921, https://doi.org/10.5194/hess-21-897-2017.

, S. B. Kapnick, G. A. Vecchi, J. A. Smith, P. C. D. Milly, and L. Jia, 2018: 100-yr Lower Mississippi floods in a global climate model: Characteristics and future changes. J. Hydrometeor., 19, 1547-1563, https://doi.org/10.1175/JHM-D-18-0018.1.

Vecchi, G. A., and Coauthors, 2014: On the seasonal forecasting of regional tropical cyclone activity. J. Climate, 27, 7994-8016, https://doi.org/10.1175/JCLI-D-14-00158.1.

Yang, X., and Coauthors, 2015: Seasonal predictability of extratropical storm tracks in GFDL's high-resolution climate prediction model. J. Climate, 28, 3592-3611, https://doi.org/10.1175/JCLI-D-14-00517.1. 